\title{
Experimental and Analytical Investigation of Drilling of Sandwich Composites: A Review
}

\author{
Patil A.A. ${ }^{1}$, Shende M.D. ${ }^{2}$ \\ ${ }^{1}$ (Department of Mechanical Engineering, SND COE YEOLA NASHIK) \\ ${ }^{2}$ (Department of Mechanical Engineering, SND COE YEOLA NASHIK)
}

\begin{abstract}
A composite material is made out of a mixture or a combination of two or more distinctly differing materials which are insoluble in each other and differ in form or chemical composition. The technological and commercial interest in composite material lies in their superior properties of strength-to-weight, stiffness-toweight, fatigue and thermal expansion compared to metals. Extensive use of composite in application such as rockets, satellites, missiles, light combat aircraft, advanced light helicopter and trainer air craft has shown that India is on par with the advanced countries in the development and use of composites in this area.

Drilling is probably the most important conventional mechanical process and it is the most widely used machining operation. Prediction of cutting forces for any set of cutting parameters is essential in optimal design and manufacturing of products. It has been predicted that most of the problem associated with hole making operation, such as drilling, can be attributed to the force generated during cutting operation. Many developments and experiments are going on drilling of Sandwich composite for damage free drilling along with the quality of the hole and the effect of tool geometry and tool material.

This paper aims at the comprehensive analytical and experimental investigation work done on the composites material. The conclusion of the paper discusses the development and outlines the trends for the research in this field.
\end{abstract}

Keywords: Drilling, Delamination, Delamination factor, thrust force, Design of Experiment, Taguchi Analysis, ANOVA

\section{Introduction:}

Engineering materials are evolving faster and the choice is wider than ever before. Many an industry has transformed significantly over the past few decades. This is mainly because of the advancement in materials, processes, and computational capabilities. Advanced high - tech industries adopted new materials and processes; replacement of mild steel with high strength steel, lighter non - ferrous alloys, such as aluminum and magnesium alloys, plastics, and composites. Many industries developing high strength, low weight materials for wide applications such as composite materials.

There are many parameters that will affect the drilling of composite material. Many researchers have done the experiments and analytical work to get the quality hole. By evaluating these experiments they provided the design function which increase the efficiency of the process and reduce the undesirable features. The feed rate and speed along with the thrust force is the most important factor which affects the delamination in drilling. Researchers provided feasible and effective methods for evaluating of drilling induced delamination factor in drilling of composite material. Present paper gives the review of the some researchers work on drilling of composite material and work on Sandwich composite material.

\section{Work on Drilling of CFRP Composites}

C. C. Tsao [1] analyzed the Taguchi method for drilling quality associates with core drill. The thrust force and surface roughness of core drill with drill parameters (grit size of diamond, thickness, feed rate and spindle speed) in drilling Carbon Fiber Reinforcement Plastic (CFRP) laminates was experimentally investigated. Composite material for drilling was fabricated using autoclave molding. A L27 ( $3^{13}$ ) orthogonal array and signal-to-noise $(\mathrm{S} / \mathrm{N})$ were employed to analyze the effect of drill parameters. Using Taguchi method for design of a robust experiment the interaction among factors is also investigated. For thrust force, thickness and feed rate are the most significant factors and for surface roughness, the feed rate and spindle speed are the most significant factors in drilling CFRP laminates as experimentally and analytically obtained. In general high speed and low drilling feed rate are recommended for the production of delamination free and good surface finish holes in epoxy composites.C.C. Tsao et al. [2] presented a prediction and evaluation of delamination factor of Carbon Fiber Reinforced Plastic (CFRP) in use of twist drill, candle stick drill, and saw drill. The experiment was conducted to study delamination factor under various cutting condition. They established the correlation between feed rates, spindle speed and drill diameter with induced 
delamination in a CFRP laminate based on Taguchiees method and the analysis of variance (ANOVA). In order to observe the influence degree of control factors (feed rate, spindle speed and drill diameter) Taguchi method is considered. Namely a L9 $\left(3^{4}\right)$ orthogonal array was employed. An ultrasonic C-Scan is used to examine drilling induced delamination. The original and binary images were taken from the ultrasonic C-Scan as shown in figure 2.1. Based on the binary images, the drilling delamination factor is determined by the ratio of maximum diameter ( $D_{\mathbf{m a x}}$ ) of the delamination zone to the hole diameter $(\mathrm{D})$. The value of the delamination factor $(F \mathbf{d})$ can be expressed as follows,

$\mathrm{F}_{\mathbf{d}}=\mathrm{D}_{\mathbf{m a x}} / \mathrm{D}$

Where the unit of $D_{\max }$ and $\mathrm{D}$ is the pixel

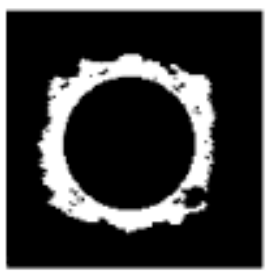

(a)

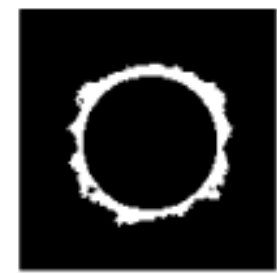

(b)

Figure 2.1: Ultrasonic C-Scan showing the extent of drilling-induced delamination for different drills (feed rate, $0.01 \mathrm{~mm} / \mathrm{rev}$; spindle speed, $1000 \mathrm{rpm}$; drill diameter, $8 \mathrm{~mm}$ ).(a) twist drill (b) candle stick drill (c) saw drill. [2] Delamination factor with ultrasonic C-Scan is shown in figure 2.2. They resulted as feed rate and drill diameter are seen to make the largest contribution to the overall performance and the candle stick drill and saw drill cause a smaller delamination factor than twist drill.

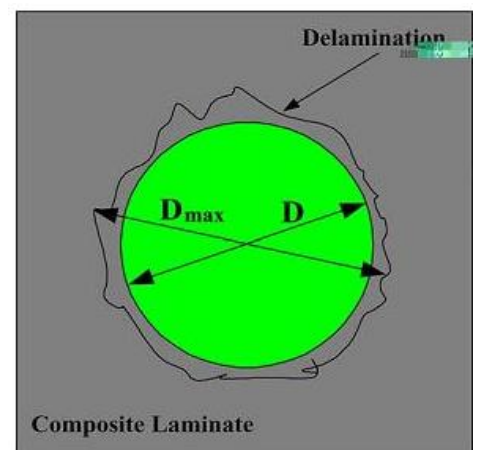

Figure 2.2: Scheme of the delamination factor with ultrasonic C-Scan [2]

C. C. Tsao [3] investigated the effect of drilling parameters (diameter ratio, feed rate and spindle speed) on delamination by various step core drill. Three step core drills (step-core-twist drill, step-core-candlestick drill and step-core-saw drill) in drilling of carbon/epoxy composite material have been investigated. The Taguchi method with orthogonal array of L18 $\left(2 * 3^{7}\right)$ and signal-to-noise ratio was selected to realize the effect of drilling parameters. He given the experiment results are for inside geometry saw drill can be drilled with lower delamination during the first drilling cycle. The drilling induced-delamination of various stepcore drill increases with decreases in diameter ratio and spindle speed and increase in feed rate. He obtained good correlation predictive equations of various step-core drills on delamination by employing multi-variables regression. K. T. Voisey et al. [4], worked on fiber swelling during laser drilling of carbon fiber composite. Three types of carbon fibers were used in them work: T300, high modulus (HM) andP100fibers.Scanning electron microscopy (SEM) and Raman spectroscopy have been used to investigate the effect of fiber type on the extent of laser-induced fiber swelling. It has been established that extensive swelling only occurred with low modulus, poly acrylo-nitrile (PAN)-based fibers. Based on Raman spectra obtained from both as-received and laser drilling fibers, the swelling mechanics is attributed to simultaneous structural rearrangement and rapid, heating induced volatilization of impurities. C. Tsao [4] experimentally investigated the thrust force of step drill with drilling parameters (step angle, stage ratio, feed rate and spindle speed) in drilling carbon fiber reinforced plastic (CFRP) laminates. Linear regression analysis (Taguchi method) and radial basis function network (RBFN) used to predict of thrust force Produced by step drill. In Taguchi methodology L27 $\left(3^{13}\right)$ orthogonal array used for checking interaction among the factors and signal-to-noise ratios used for calculation each control factor. For adopting the input-output mapping the RBFN system is used. 
Results were obtained are thrust force increases with feed rate, and decreases with spindle speed, that is to get higher thrust force without delamination requires a low feed rate and high spindle speed. The conformation test was also carried out. In the test, RBFN has been shown to be a better predictive model than multi-variable linear regression analysis. Following figure shows the Comparison of thrust force between prediction and experiment

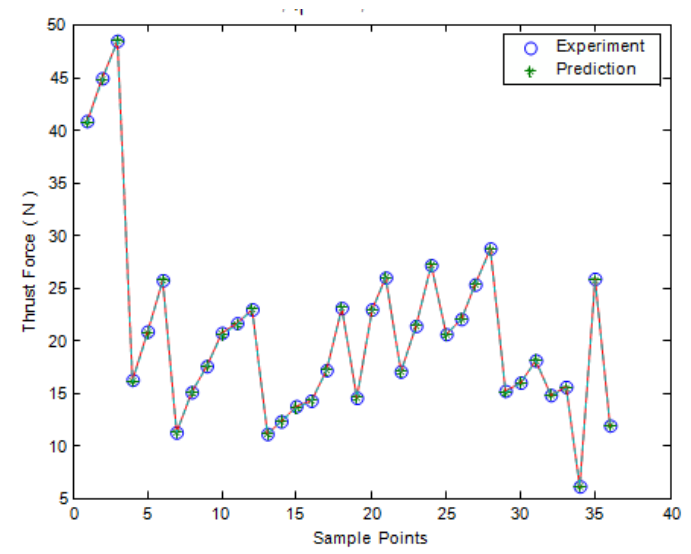

Fig. 2.3 Comparison of thrust force between prediction and experiment.

C. C. Tsao [5], worked on thrust force and delamination of core-saw drill during drilling of carbon fiber reinforced plastics (CFRP). To obtain smaller-the-better characteristics he optimized the drilling parameters using Taguchi method. From Taguchi methodology, in order to observe the degree of influence for drilling parameters (diameter ratio, feed rate and spindle speed) in drilling CFRP laminates, a $\mathrm{L}_{18}\left(2 * 3^{7}\right.$ ) orthogonal array and signal-to-noise $(\mathrm{S} / \mathrm{N})$ were employed. The experiment carried out by Tsao, shows that the feed rate and spindle speed are the main parameters among the three control factors that influence the thrust force and delamination. The effect of diameter ratio was relatively insignificant. A small feed rate was shown to produce low thrust force in drilling, which can reduce the extent of induced delamination. P.Rahme et al. [5], proposed operating procedure to reduce different defects generated by drilling thick carbon epoxy plate at the entry, on the wall and on the hole exit. Defects came in experiment are tearing of the layers at hole entry. On the wall defects are tearing of fibers in packets and matrix, degradation of the matrix and crosswise cracking by shearing in different layers. Defects at hole exit are bending of fibers and tearing \& breaking of the fibers. Several solution are given to avoid this delamination as evinced in the tests and experimental observation; drilling with support shim reduces delamination on exit and introduced a fiberglass woven significantly limits propagation of cracks, while optimum drill geometry and feed rate selection enhances the quality of the hole.Y Quan et al. [6], experimentally investigated drilling temperature of drilled hole wall of CFRP composites by means of inserted thermocouples. The effect of work piece thickness, drill diameter and material, drill rotation rate and feed on the drilling temperature were analyzed. The investigation results indicate: the thicker the work piece, the higher the drilling temperature will be; drill diameter has no obvious effect on drilling temperature, but drill materialsee effect was significant; drill rotation rate and feed has complex and synthetically effect on drilling temperature, that is, drilling temperature depends on both of material removal rate and cutting time. Usually cutting temperature in the drilling of thin CFRP laminates will be below $250{ }^{\mathrm{O}} \mathrm{C}$, which has no notable effect on drills ${ }^{\text {ee }}$ performance, but mat affect drilled hole quality.

\section{Work on Drilling of GFRP Composites}

S. Arul et al. [7] investigated the effect of tool material on dynamics of GFRP composites. Drilling trials have been carried out on glass fiber reinforced plastics (GFRP) with plain high speed steel (HSS), TiN coated HSS and tipped tungsten carbide drills. Found that most of the defects in drilling of composites are due to thrust force experienced by the work piece. They done thrust modeling (evaluation of critical thrust) and founded out effect of tool material on thrust, effect of tool material on flank wear, effect of tool material on hole shrinkage and delamination factor. Figure 3.1 illustrated the relative hole quality between the tool material. It can be seen that the stress whitening layer around the exit of the hole increases with the number of holes drilled. As seen in figure, lower order shrinkage can be seen in the case of the tipped tungsten carbide drills. In drilling with HSS and TiN coated HSS, increases of thrust and delamination factor around 30 holes, indicate that 30 is the limiting number of holes to be drilled while with cemented tungsten carbide drill 50 is the limiting number of holes to be drilled for defect tolerancing. Coating of drills does not give much improvement 
in drilling performance. Tipped carbide drills performed better than HSS.

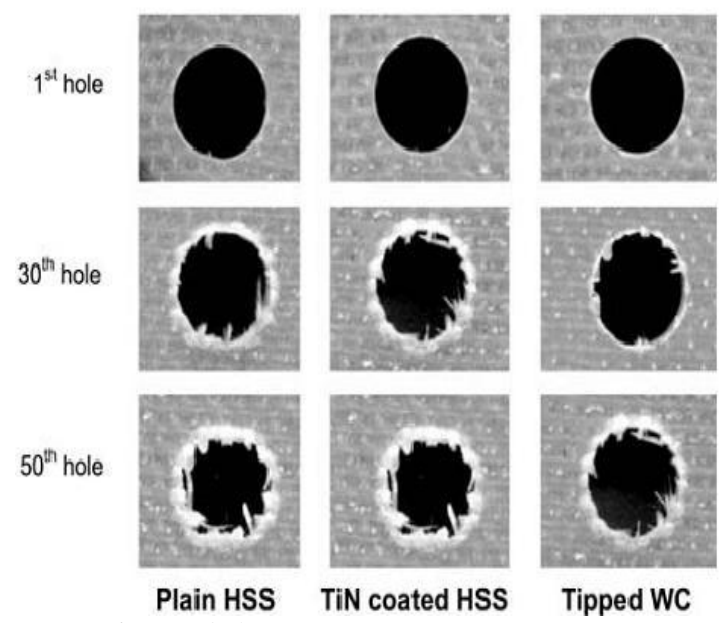

Figure 3.1: The relative hole quality [7]

Birhan Isik et al. [8] presented a new comprehensive approach to select cutting parameters for damage factor in drilling of glass fiber reinforced polymer (GFRP) composite material. The influence of drilling on surface quality of woven GFRP plastic composite material was investigated experimentally. Damage factor was investigated based on hole entrance and exit. Deformation at the hole entrance and exit were observed by MITUTOYO TM-500 digital indicator microscope. Damage factor (DF) was determined by the ratio of maximum deformation diameter to the hole diameter. Analysis of variance (ANOVA) test was applied to the experimental results. From the experiment they resulted as increasing of cutting speed increases DF at both hole entrance and exit. Increasing of feed increases DF at hole exit and decrease DF at hole entrance. Increasing of point angle increases DF at both hole entrance and exit. Delamination, chipping and spalling damage mechanism were observed in drilling chopped and continuous winding composites. Figure 3.2 illustrate the Peel-up and Push-up delamination at entry and exit of the drilling of FRP laminates.

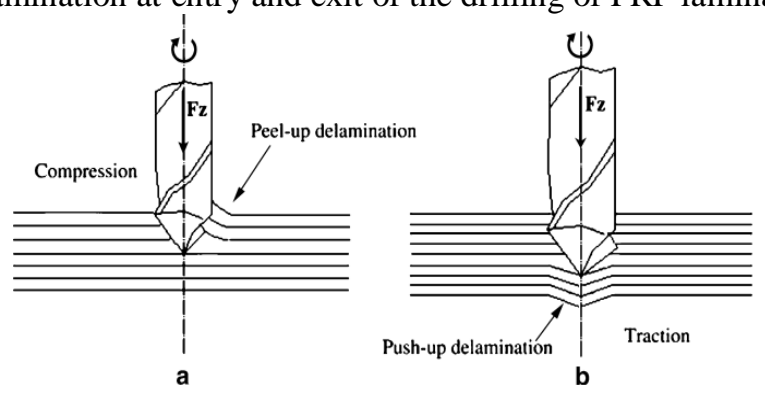

Figure 3.2: Delamination at hole entrance (a) and exit (b) when drilling FRP laminates [8]

J. Campos Rubio et al. [9], worked on High speed machining to realize high performance drilling of glass fiber reinforced plastics (GFRP) with reduced damage. Results presented suggest that the adjusted delamination factor is more sensitive to the machining parameters (spindle speed and feed rate) than the conventional delamination factor. Cutting temperature is elevated with spindle speed, thus promoting the softening of the matrix and inducing less delamination. For larger material removal rates associated with minimal delamination, higher spindle speed should be used when drilling GFRP. Following figure shows the effect of feed speed on the conventional (Fd) and adjusted (Fda) delamination factor using "Brad \& Spur" drill WN R FK when high speed drilling at 40000rpm

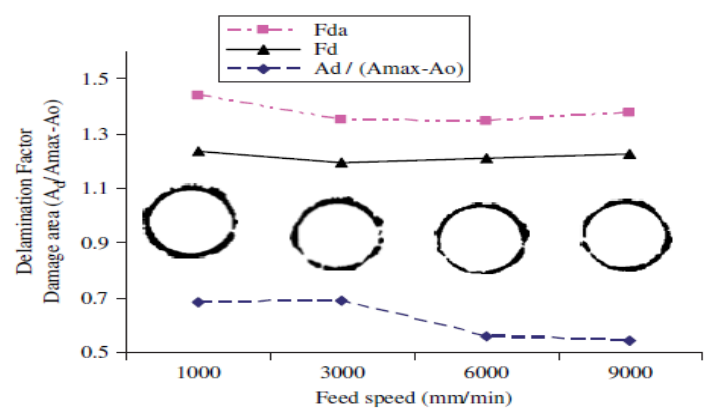

Fig.3.3 The effect of feed speed on the conventional (Fd) and adjusted (Fda) delamination factor using "Brad \& 
Spur" drill WN R FK when high speed drilling at $40000 \mathrm{rpm}$.

Jose Mathew et al. [10], experimentally investigated the effect of geometry of a trepanning tool on thrust and torque during the drilling of uni-directional glass fiber- reinforced plastic (UD-GFRP). Investigation was aimed at exploring the possibility of reducing the thrust and torque by using the concept of trepanning. An optimum geometry of the trepanning tool for drilling GFRP materials was obtained. Experiments are carried out with the analytical methods. This trepanning tool produced about 50\% less thrust and about 10\% less torque as compared to twist drills. The holes were found to be of good and acceptable quality. The investigations have revealed that the performance of the trepanning tool is superior to that of conventional twist drills in terms of thrust, torque and hole quality. Figure 3.4 shows comparison of the hole quality produced by the trepanning tool and twist drill.

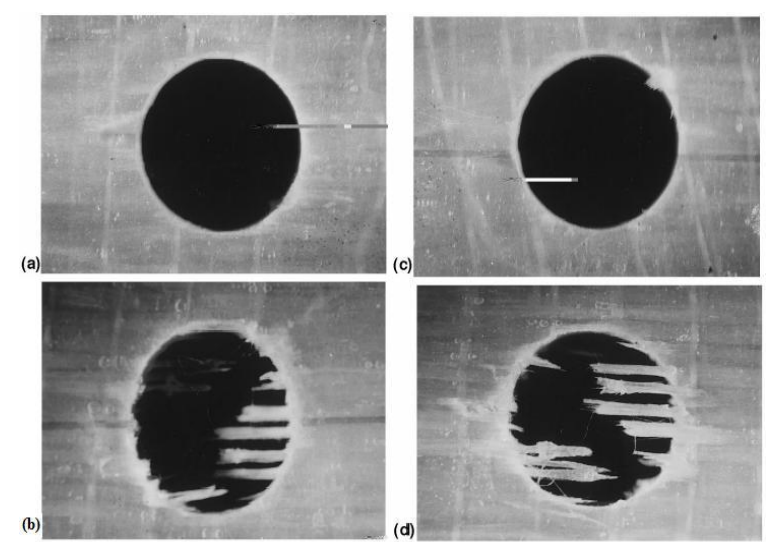

Figure 3.5: comparison of the hole quality produced by the trepanning tool and twist drill (GFRP, 4-mm thick UD laminated; tool diameter $10 \mathrm{~mm}$; cutting speed $50 \mathrm{~m} / \mathrm{min}$; feed $0.2 \mathrm{~mm} / \mathrm{rev}$ ): (a) hole quality at entry with trepanning tool; (b) hole quality at entry with twist drill; (c) hole quality at exit with trepanning tool; and (d) hole quality at exit with twist drill) [10].

Figure 3.5 also shows from (a) to (d) the quality of holes at the entry and exit produced by the trepanning tool and the twist drill. Fiber pullout was almost absent in trepanned holes. It can be seen that the overall quality of the holes produced by trepanning tools is superior to those produced by the twist drills under identical cutting conditions.

\section{Drilling of Metal Matrix Composite}

S. Basavarajappa et al. [11], discussed the influence of cutting parameters (cutting speed and feed rate) on drilling characteristics of hybrid metal matrix composite (MMCs). For studying they have taken two hybrid metal matrix material Al2219/15SiCp (SiCp reinforced composite) and Al2219/15SiCp-3Gr (SiCpgraphite reinforced composite). The composites are fabricated using stir casting method. The Taguchi design of experiments and analysis of variance (ANOVA) are employed to analyze the drilling characteristics of these composites. The experiment were conducted to study the effect of spindle speed and feed rates on feed force, surface finish and burr height using solid carbide multifacet drills of $5 \mathrm{~mm}$ diameter. The result shows that the dependent variables are greatly influenced by the feed rate rather than the speed for the both composites. The ceramic-graphite reinforced composite has better machinibility than those reinforced with SiCp composite. Figure $4.1 \& 4.2$ shows the response plot of the ANOVA Analysis for various factors.
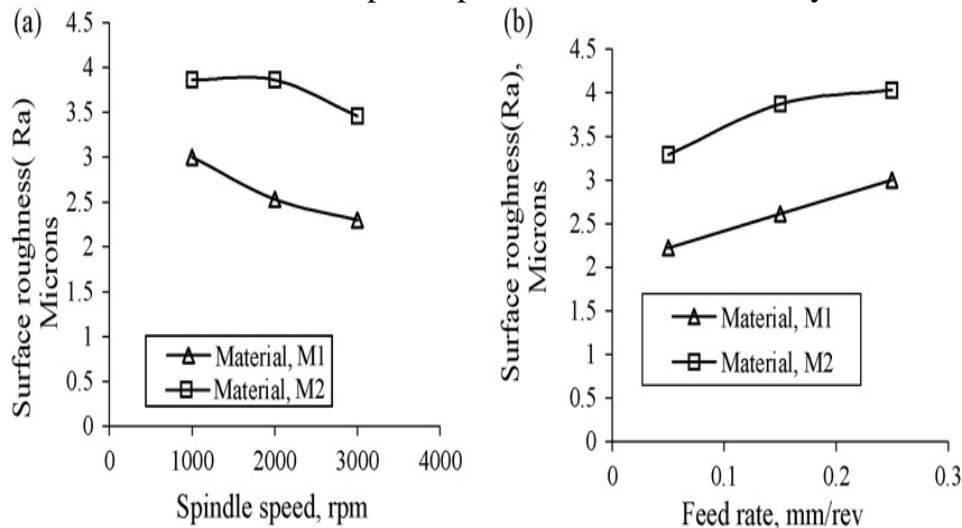

Fig. 4.1- Response plots of the ANOVA analysis: (a) variation of surface finish vs. spindle speed and (b) variation of surface Finish vs. feed rate. 

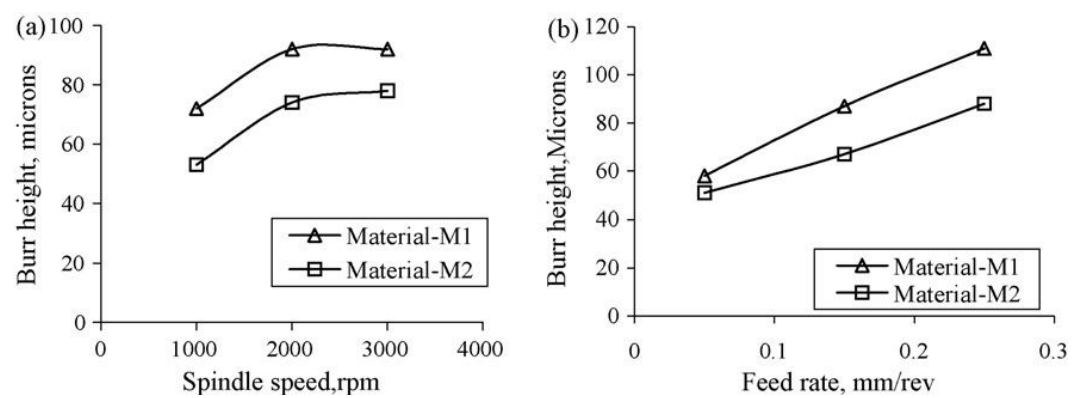

Fig. 4.2 - Response plots of the ANOVA analysis: (a) variation of burr height vs. spindle speed and (b) variation of burr height vs. feed rate.

A. Noorul Haq et al. [12], presented optimization of drilling parameters namely cutting speed, feed rate and point angle with the consideration of multi responses such as surface roughness, cutting force and torque on drilling $\mathrm{Al} / \mathrm{SiC}$ metal matrix composite. Experiments are conducted on LM25-based aluminium alloy reinforced with green bonded Silicon Carbide of size $25 \mu \mathrm{m}$. Drilling test was carried out using TiN coated HSS twist drill of $10 \mathrm{~mm}$ diameter under dry condition based on orthogonal array with gray relational analysis. A gray relational grade is obtained from the gray analysis. Confirmation test was conducted to validate the test result. The surface roughness, cutting force and torque values collected under different cutting condition for various combination of drilling parameters and they predicted as gray relational analysis in the Taguchi method for the optimization of multi response problems is very useful tool for predicting cutting parameters in drilling of $\mathrm{Al} / \mathrm{SiC}$ metal matrix composite. The best performance characteristics were obtained with TiN coated HSS twist drill.

\section{Modeling and Analysis in drilling of Composite}

R. Vimal Sam Singh et al. [13] investigated the thrust force and torque developed during drilling of Glass Fiber Reinforced Plastic (GFRP) composite according to the L27 orthogonal array experiments. They developed Fuzzy rule based model for predicting thrust force and torque in drilling of GFRP composite. The results indicated that the increase of spindle speed reduces the delamination in drilling of composite. The reason being at higher cutting speed, the material removal action is high and it leads to low delamination on the drilled composite plates which in turn reduces the thrust force and torque in drilling of composite material. The increase of feed rate and drill diameter increases the thrust force and torque in drilling of composite material. The increases of drill diameter and feed rate increases the contact between the work piece material and it leads to high thrust force and torque. By keeping the low feed rate and drill diameter one can reduces the delamination and torque in drilling of composite materials. Rule based fuzzy logic model can be effectively used to predict the thrust force and torque in grilling GFRP composites. Following figure shows the variation of test result.
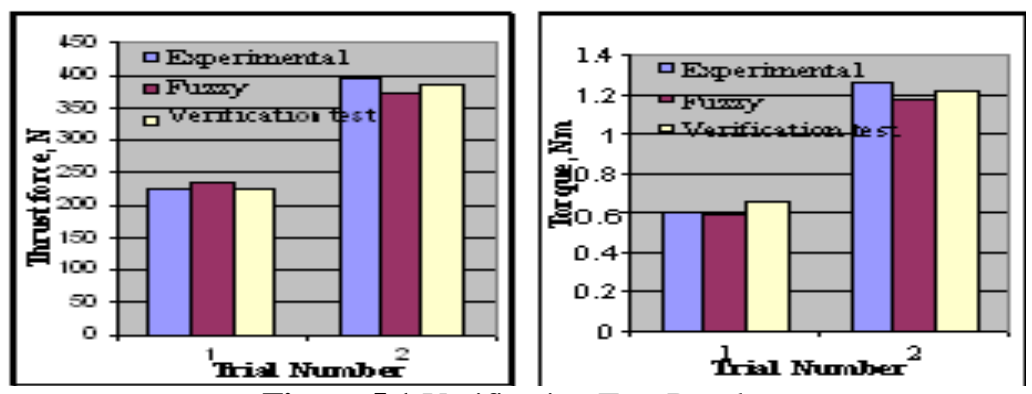

Figure 5.1 Verification Test Results

Marta Fernandes et al. [14] investigated the force and torque produced during drilling of carbon fiber using a one shot drill bit. It is also showed that how tool wear and thickness of the work piece affect the thrust force and torque throughout the drilling process. The typical thrust forces and spindle torques produced during drilling of carbon-epoxy composite using the one shot drill bit can be founded by dividing drilling process into five drilling stages. In part II they developed the mathematical model which successfully estimates maximum thrust force and torque to improve the quality of the hole in drilling of carbon composites using one shot drill bit. Figure 5.2 shows the measured and estimated maximum thrust force. 


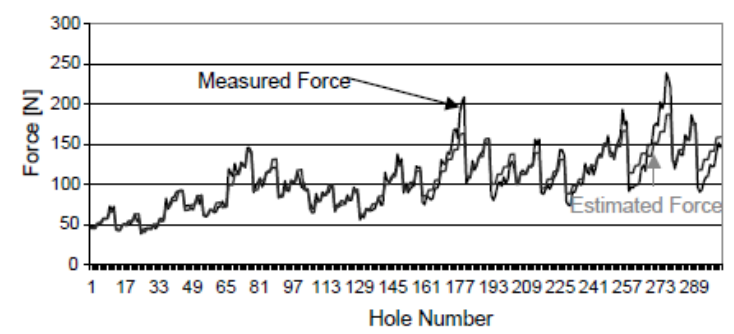

Fig.5.2 Measured and estimated maximum thrust force.

R. A. Kishore et al. [15], determined the optimal set of cutting parameters (cutting speed, the feed rate) and the drill point geometry that result in the maximum residual tensile strength in drilled unidirectional Glass Fiber Reinforced Epoxy composite using the Taguchi method. In Taguchies methodology typical control factors for the drilling of unidirectional glass fiber reinforced epoxy composite include drill point geometry, feed rate and cutting speed. A L9 orthogonal array and signal-to-noise ratio were employed by Taguchi method. The term signal represents the desirable component of the output characteristics, which is close to its specific target value. The term noise represents the undesirable component and its measure of the variability of the output characteristics. The Taguchi method uses the signal-to-noise ratio $(\mathrm{S} / \mathrm{N})$ to express the scatter around a target value. The figure 5.3 shows relative effect of different parameters on residual tensile strength of the drilled glass fiber reinforced composite laminates. It can be seen that all the three parameters (drill point geometry, feed rate and cutting speed) have strong influence on residual strength of drilled composite. They established optimum levels of the drill point geometry, the cutting speed and feed rate for getting maximum residual tensile strength in drilled UD-GFRP laminates. They concluded that the drilling induced damage at higher cutting speeds severely affects the residual tensile strength of drilled laminates. Conformation tests were also carried out to verify the predicted optimal conditions. Values of estimation gain and conformation gain were found close each other. Following figure shows the $\%$ contribution of process parameters on residual tensile strength

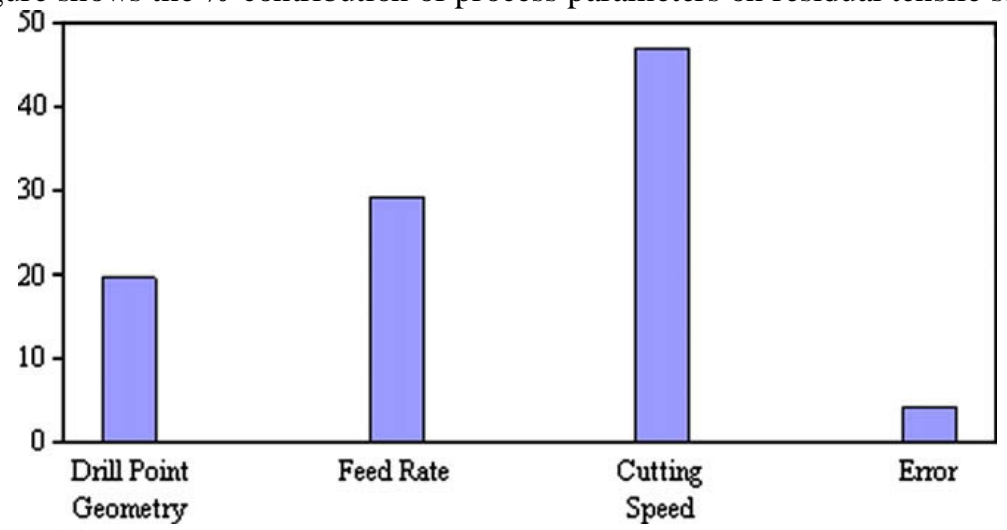

Figure 5.3: \% contribution of process parameters on residual tensile strength [15]

V. N. Gaitonde et al. [16] presented the effect of process parameters (cutting speed, feed rate and point angle) on delamination during high speed drilling of carbon fiber reinforced plastic (CFRP) composite. The drilling experiment using cemented carbide (K20) twist drills were performed based on full factorial design (FFD). They developed second order non-linear regression mathematical model based on response surface methodology (RSM). The model developed was validated through analysis of variance (ANOVA). It has been observed from analysis that high speed cutting plays a major role in reducing damage at the entrance of hole and combination of low feed rate and point angle is also essential in minimizing delamination during drilling of CFRP composite. 
(a)
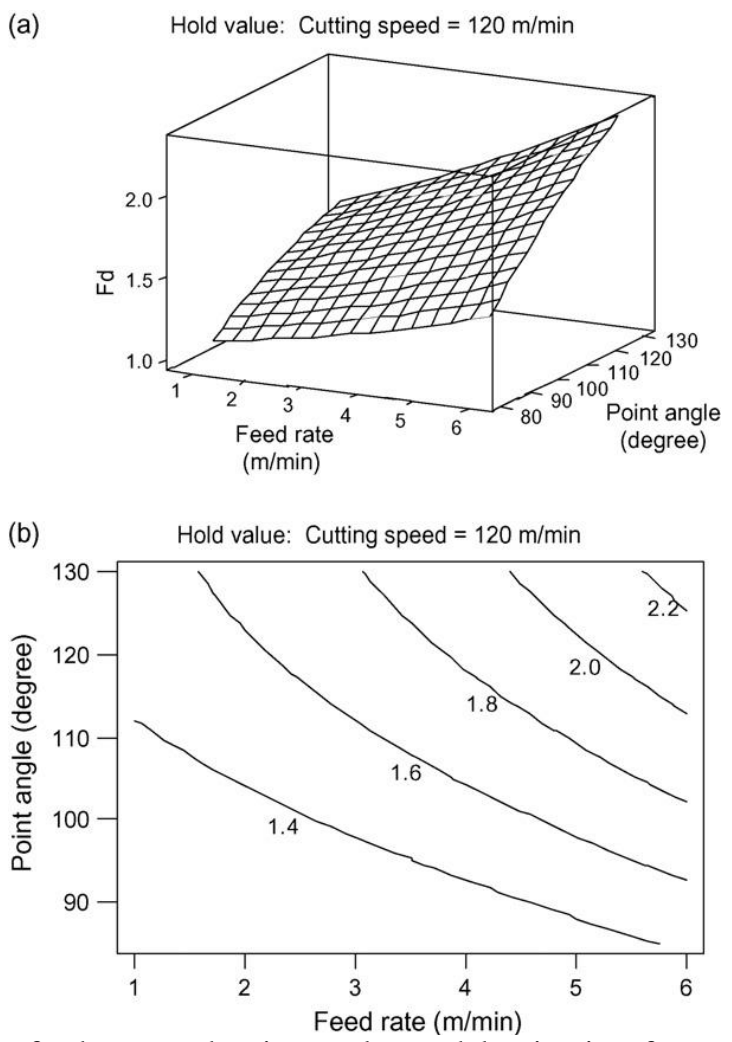

Fig.5.4 -Interaction effect due to feed rate and point angle on delamination factor for a cutting speed of 120 $\mathrm{m} / \mathrm{min}$. (a) Response surface plot. (b) Contour plot.

Pierre Rahme et al. [17] developed an orthotropic analytical model in order to calculate the critical force of delamination during drilling and numbers of hypotheses for loading are proposed. This critical axial load is related to the delamination condition and the mechanical characteristics of the composite material machined. A numerical model is also drawn up to allow for numerical validation of the analytical approach. Figure 5.5 gives the view of orthotropic analytical model used for the drilling.

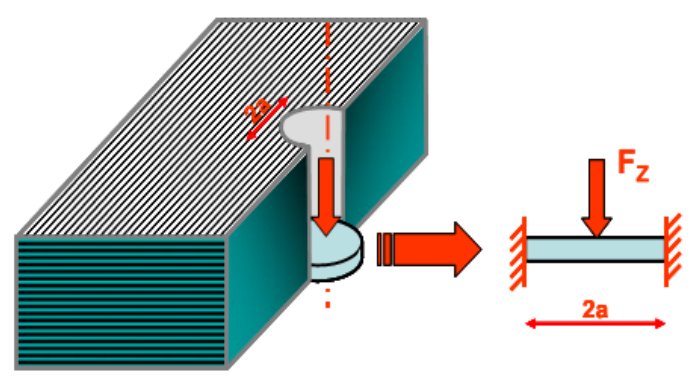

Figure 5.5: Orthotropic analytical model used when drilling [16]

Experiment was also carried out by using tapered sharpened twist drill. Comparative study was also done and resulted that the model is helpful to control critical thrust force on delamination and to optimize cutting condition and can be adapted to different cutter. Following figure shows the different loading models with the experimental results.

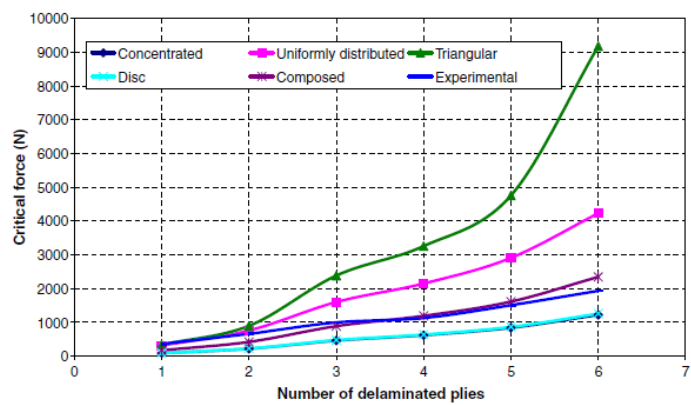

Fig.5.6 Comparison of the different loading models with the experimental results H. Ho-Cheng [18], presented analytical approach to study the delamination during drilling by water jet 
piercing. The analysis used fracture mechanics with plate theory to describe the mechanism of delamination. The developed model predicts an optimal water jet pressure for no delamination as a function of hole depth and material parameters (opening -mode delamination fracture toughness and modulus of elasticity). Because water jet drilling, in spite of its advantage of no tool wear and thermal damage, often creates delamination in composite laminates at bottom. The below figure shows water jet induced delamination at exit.Ho-Cheng achieved good agreement with data obtained from water jet drilling of graphite epoxy laminate. He developed mechanics of water jet induced delamination and obtained analytical approach for water pressure, which is function of material properties and the uncut thickness, to avoid delamination. The predicted optimal water jet pressure can be applied in a control scheme for maximizing the productivity of water jet drilling of composite laminates. Figure 5.7 gives the water jet induced delamination at the exit of the hole while drilling.

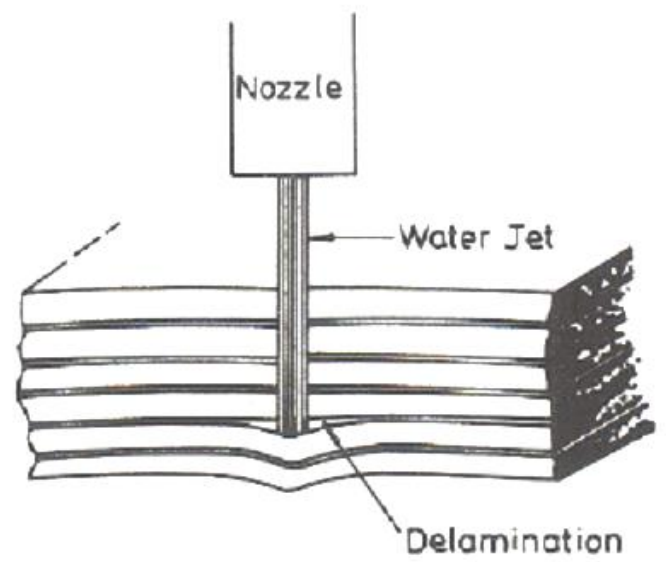

Figure 5.7: Water jet induced delamination at exit [17]

\section{Effect of tool or cutting parameters on drilling of Composite}

C.C. Tsao et al. [19] investigated the effect of eccentric twist drill and eccentric candle stick on delamination in drilling of fiber reinforced material. Comprehensive delamination models for the delamination induced by an eccentric twist drill and an eccentric candle stick drill in the drilling of composite material has been constructed. The analytical results were obtained based on classical elasticity, linear elastic fracture mechanics and energy conservation. He showed a lower critical thrust force results if an eccentric twist drill or an eccentric candle stick drill is used for drilling so that a lower feed rate has to be used to prevent delamination damage.following figure shows the Critical thrust force ratio between eccentric candle stick drill and twist drill.

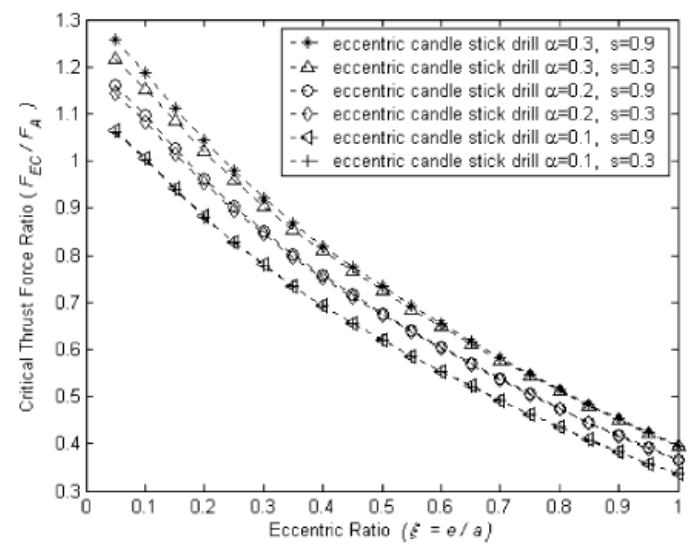

Fig.6.1 Critical thrust force ratio between eccentric candle stick drill and twist drill.

By this model he has given the guide for drill design and tool regrinding, especially when the eccentric ratio affect the critical thrust force.

C.C. Tsao et al. [20], studied analytically and experimentally that delamination in drilling can be correlated to the thrust force of the drill. Early reference reported models of drilling-induced delamination, however, the effect of chisel edge length and pilot hole diameter on delamination is rarely discussed. Investigators have derived that with pre-drilled pilot hole, the delamination can be reduced significantly, and an optimal range of diameter of the pilot hole associated with chisel edge length is also derived. Tsao compared results of critical thrust force with pilot hole and without pilot hole which is shown in figure 6.2 


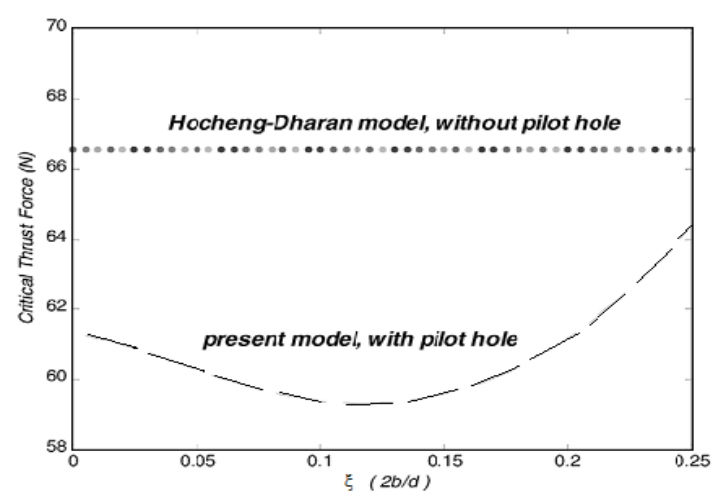

Figure 6.2 Comparison of the critical thrust force predicted by C.C. Tsao and H. Hocheng model with pilot hole and by Hocheng and Dharan model without a pilot hole [20].

C. C. Tsao et al. [21] showed the delamination can be effectively reduced or eliminated by slowing down the feed rate when approaching the exit and by using back-up plates to support and counteract the deflection of the composite laminate leading to exit side delaminations. They predicted the effect of back up plate on delamination in drilling of woven WFC200 fabric carbon fiber (made by autoclave molding) composite material using saw drill and core drill. The critical drilling thrust force at the onset of delamination is calculated and compared with that without backup. Figure 6.3 clearly indicates the effectiveness in use of backup plate foe saw drill and core drill. They obtained theoretical results based on classical elasticity, linear elastic fracture mechanics and energy conservation law. Results obtained by them are agreed with industrial experience, that drill allows for larger critical thrust force can be operated at larger feed rate without delamination damage.

(a)

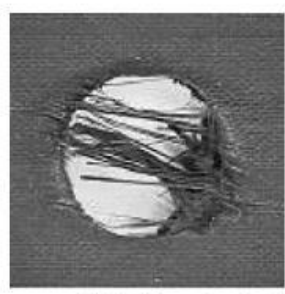

saw drill (without backup)

(c)

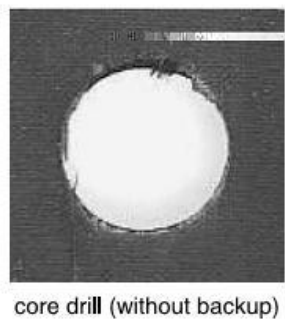

(b)

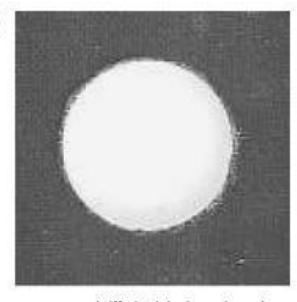

saw drill (with backup)

(d)

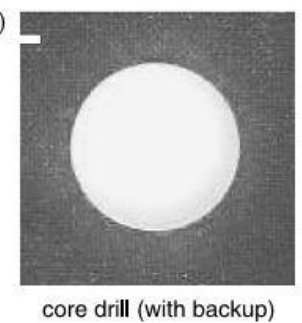

Figure 6.3: Photograph of drilling-induced delamination for saw drill and core drill. (Spindle speed, $1000 \mathrm{rpm}$; feed rate, $0.016 \mathrm{~mm} / \mathrm{rev})[21]$

M. K. A Mohd Ariffin et al. [22], focused on an optimization of the drilling cutting process for the composite sandwich panel. A glass fiber reinforced plastic (GFRP) sandwich part number of BMS 4-17 form Boeing Corporation is used for testing. They provided machinist with a simple procedure in order to minimize the damage events occurring during drilling process for composite material. A statistical approach is used to analyze the experiment data and it is called as design of experiment (DOE). Design of experiment (DOE) is a toll used to identify process regions that lead to superior product characteristics. Here, DOE was used to investigate the effect of drill material and drilling process parameters such as cutting speed, fed rate and drill hole quality. The result from the study shows that the minimum damage length is $0.05 \mathrm{~mm}$ and the maximum is $0.44 \mathrm{~mm}$ which was done at $3000 \mathrm{rpm}$, feed rate of $80.2 \mathrm{~mm} / \mathrm{rev}$ for HSS and spindle speed at 500 $\mathrm{rpm}$, feed rate of $246.8 \mathrm{~mm} / \mathrm{rev}$ using carbide tool respectively. Interaction between cutting speed and feed rate are the most significant in controlling the level of damage during drilling process. On the other hand, the interaction of cutting tool material and cutting speed are the most insignificant.

N. S. Mohan et al. [23], investigated process parameters (speed, feed rate, drill size and specimen thickness) on cutting force and torque during drilling of glass fiber polyester reinforced composites. The research outlined the Taguchi optimization methodology and ANOVA was used to study effect of process 
parameters on machining process. A series of experiments was conducted using TRIAC VMC CNC machining center to relate the cutting parameters and material parameters on the cutting thrust and torque. From the analysis of the Taguchi method results are indicated that among the all significant parameters, speed and drill size are most significant influence on cutting thrust than the specimen thickness and feed rate. study of response table indicated that the specimen thickness and drill size are the significant parameters of torque. From the interaction among process parameters, thickness and drill size together is more dominant factor than any other combination for the torque characteristic.

\section{Work On Sandwich Matrerial}

Byoung Jung Kim et al. [24] investigated experimentally the load transfer characteristics of the partial type insert for composite sandwich panels with respect to the insert shape. The static and dynamic pull out tests of the composite sandwich panels composed of an aluminum honeycomb core, two laminates of carbon fiber/epoxy composite and aluminum insert, were performed. From the experiments, the effect of the insert shape on the mechanical characteristics of composite sandwich panels was evaluated.
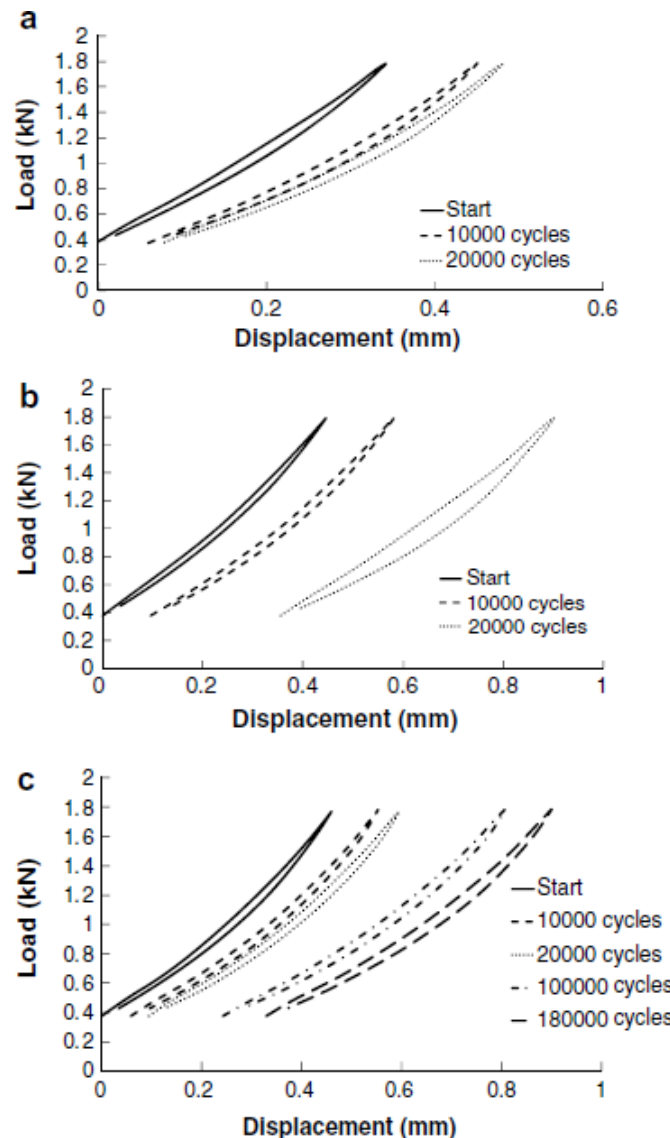

Fig.7.1 Load-displacement curves related to dynamic pull out tests on composite Sandwich panels with various shapes of inserts: (a) cylindrical shape, (b) circular I beam shape and (c) dumbbell shape.

A. Paolozzi et al. [25], presented study on frequency shifts induced by debonding damage in a carbon-fiber reinforced plastic sandwich panel and widely interpreted. He compared with previously obtained numerical results and that are satisfactory. Specifically, the possibility of assessing the extension of the debonded area is experimentally verified. The validation of the numerical results also showed the possibility of determining the damage location. Finally, very good agreement between numerical and experimental results is showed for the cross-over between the first and the second bending models.

Giuseppe Demedio et al. [26], shows experimental investigation was carried out to estimate the static and fatigue behavior of specimens made up from steel plates and sandwich composite panels joined together by either blind or mechanical lock fasteners. A preliminary study was carried out in order to analyze the drilling operation of sandwich panels to determine the best values of parameters to use for fasteners installation. For all panels a common electric drill of $3000 \mathrm{rpm}$ with an automatic drilling rate of $4 \mathrm{~mm} / \mathrm{min}$. and $27.5 \mathrm{~mm} / \mathrm{min}$. was used for GR/GL fibers and KEV fibers reinforced panels respectively. A Vidia conventional drill has been successfully used in drilling panels even though their use is not commonly recommended for composites. That results has to be ascribed the stiffening effect of the adhesive bonding core and skin 
that elimated fuzzing and delamination around the hole. A backup plate of steel was used during drilling to reduce surface delamination and to keep the fibers from fraying. They performed a set of static tests on specimens to evaluate the possible ageing effect on mechanical properties of sandwich panels. Figure 7.2 and 7.3 shows Load displacement curve related to pull -out fatigue test on specimen $101 \& 103$ Resp.
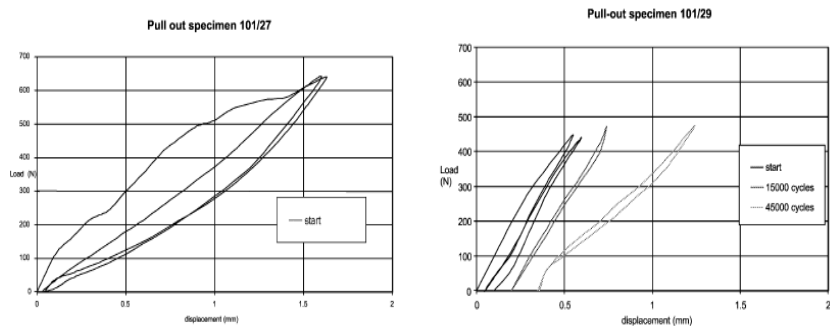

Figure 7.2 Load displacement curve related to pull -out fatigue test on specimen 101

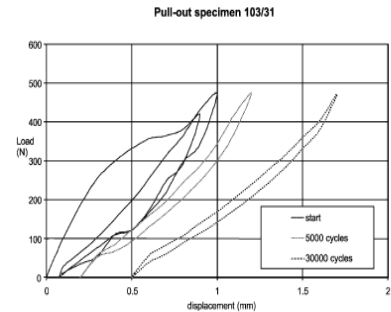
Pull out speeimen 103/34

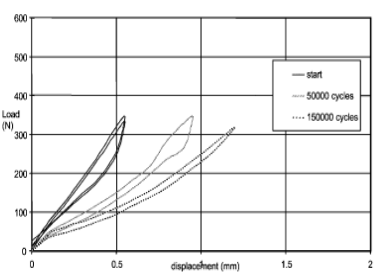

Figure 7.3 Load displacement curve related to pull -out fatigue test on specimen 103

S.C. Sharma et al. [27] investigated the fatigue characteristics of polyurethane foam-cored (PUF) composite sandwich structures using three-point bending tests carried out according to ASTM C 393. Three types of specimens (epoxy/glass-PUF-epoxy/glass, polyester/glass-PUF-polyester/glass, and epoxy/glass-PUFpolyester/glass) were considered for investigation. Experimental results indicated that degradation of stiffness occurs due to debonding and sliding between the skin and the foam during fatigue cycles. Epoxy/glass-PUFepoxy/glass sandwich structures exhibited higher bending strength along with higher stiffness degradation than the other two types of sandwich panels, due to higher initial fatigue loading. The lowest fatigue property has been obtained for the polyester/glass-PUF-polyester/glass sandwich panel specimens. Better performance of the epoxy/glass-PUF-epoxy/glass sandwich panels showed due to the superior properties of the outer thin skins. Most of the specimens failed within the foam region and not at the skin level. This situation is possibly due to debonding between the foam and the skin. The fatigue damage developed in the foam and skin has been investigated using scanning electron microscopy.

A.C. Manalo et al. [28] investigated the flexural behavior of a new generation composite sandwich beams made up of glass fiber-reinforced polymer skins and modified phenolic core material. The composite sandwich beams was subjected to 4-point static bending test to determine their strength and failure mechanisms in the flat wise and the edgewise positions. The results of the experimental investigated showed that the composite sandwich beams tested in the edgewise position failed at a higher load with less deflection compared to specimens tested in the flat wise position. Under flexural loading, the composite sandwich beams in the edgewise position failed due to progressive failure of the skin while failure in the flat wise position is in a brittle manner due to either shear failure of the core or compressive failure of the skin followed by debonding between the skin and the core. The results showed that the analytical predictions and numerical simulations are in good agreement with the experimental results.

\section{Conclusion}

The Conclusions of this review study are as follows

1. It is observed that lot of work has been done on drilling of composite material, the defect observed during drilling as well as effect of various cutting parameters and drilling parameters on drilling.

2. It is also observed that various methodology and analyzing techniques are used to improve the quality of the hole in drilling composite material, this leads to a very important area for manufacturing field to join structure.

3. Along with composite material the various works has done on the sandwich composite.

4. The debonding damage, fatigue behavior, static behavior, flexural behavior and characteristic of joining etc. were studied for sandwich composite.

5. As various parameters of sandwich composite has been studied but seldom work done on drilling of sandwich composite.

6. There is scope to study the Analytical and experimental investigation for the Drilling of Sandwich Composites. 


\section{References:}

[1] C. C. Tsao, "Taguchi analysis of drilling quality associated with core drill in drilling of composite Material"; International Journal of Advanced Manufacturing Technology, vol. 32, 2007, pp 877-884.

[2] C. C. Tsao, H. Hocheng, "Taguchi analysis of delamination associated with various drill bits in drilling of composite material"; International Journal of Machine Tools \& Manufacture, vol. 44, 2004, pp 1085-1090.

[3] C.C. Tsao, "Investigation into the effect of drilling parameters on delamination by various step-core drills"; Journal of Materials Processing Technology, vol. 206, 2008, pp 405-411.

[4] K. T. Voisey, S. Fouquet, D. Roy and T. W. Clyne, "Fiber swelling during laser drilling of cabon fiber composites"; Journal of Optics and Lasers in Engineering, vol. 44, 2006, pp 1185-1197.

[5] C. C. Tsao, "Prediction of thrust force of step drill in drilling composite material by taguchi method and radial basis function network"; International Journal of Advance Manufacturing Technology, vol. 36, 2008, pp 11-18

[6] Yanming Quan and Luhua Sun, "Experiment investigation on drilling temperature ofcomposites"; Internationa Journal of Machining and Machinability of Materials, vol. 3, nos. 3/4, 2008, pp 356-363.

[7] S. Arul, L. Vijayaraghavan, S. K. Malhotra and R. Krishnamurthy, "Influence of tool material on dynamics of drilling of GFRP composite"; International Journal on Advance Manufacturing Technology, vol. 29, 2006, pp 655-662.

[8] Birhan Isik, Ergun Ekici, "Experimental investigations of damage analysis in drilling of woven glass fiber reinforced plastic composite"; International Journal of Advanced Manufacturing Technology, vol. 49, 2010, pp 861-869.

[9] J. Campos Rubio, A.M. Abrao, P.E. Faria, A. Esteves Correia and J. Paulo Davim, "Effect of high speed in drilling of Glass Fiber Reinforced Plastic: Evaluation of the delamination factor"; International Journal of Machine Tools \& Manufacture, vol. 48, 2008, pp 715-720.

[10] Jose Mathew, N. Ramakrishnan and N. K. Naik, "Investigations into the effect of geometry of a trepanning tool on thrust and torque during drilling of GFRP composite"; Journal of Material Processing Technology, vol. 91, 1999, pp 1-11.

[11] S. Basavarajappa, G. Chandramohan and J. Paulo Davim, "Some studies on drilling of hybrid metal matrix composite based on Taguchi techniques"; Journal of Materials Processing Technology, vol. 196, 2008, pp 332-338.

[12] A. Noorul Haq, P. Marimuthu and R. Jeyapaul, "Multi response optimization of machining parameters of drilling Al/SiC metal matrix composite using gray relation analysis in the Taguchi method"; International Journal of Advance Manufacturing Technology, vol. 37, 2008, pp 250-255.

[13] R. Vimal Sam Singh, B. Latha and V. S. Senthikumar, "Modeling and analysis of thrust force and torque in drilling GFRP composite by multi-facet drill using Fuzzy logic"; International Journal of Recent Trends in Engineering, vol. 1, No. 5, May 2009, pp 66-70.

[14] Marta Fernandes, Chris Cook, "Drilling of carbon composite using a one shot drill bit Part II: Empirical modeling of maximum thrust force"; International Journal of Machine Tools \& Manufacture, vol. 46, 2006, pp 76-79.

[15] R. A. Kishore, R. Tiwari, A. Dvivedi and I. Singh, "Taguchi analysis of the residual tensile strength after drilling in glass fiber reinforced epoxy composite"; Journal of Material and Design, vol. 30, 2009, pp 2186-2190.

[16] V. N. Gaitonde, S. R. Karnik, J. Campos Rubio, A. Esteves Correia, A. M. Abrao and J. Paulo Davim, “Analysis of parametric influence on delamination in high speed drilling of carbon fiber reinforced plastic composites"; Journal of Materials Processing Technology, vol. 203, 2008, pp 431-438

[17] Pierre Rahme, Yann Landon, Frederic Lachaud, Robert Piquet and Pierre Lagarrigue, "Analytical models of composite material drilling" International Journal of Advance Manufacturing Technology, vol. 170, 2010, pp 2773-2783.

[18] H. Ho-Cheng, "A failure analysis of water jet drilling in composite laminates"; International Journal of Mechanical Tools Manufacturing, vol. 30, No. 3, 1990, pp 423-429.

[19] C. C. Tsao, H. Hocheng, "Effect of tool wear on delamination in drilling composite materials"; International Journal of Mechanical Sciences, vol. 49, 2007, pp 983-988

[20] C.C. Tsao, H. Hocheng, "Effect of eccentricity of twist drill and candle stick drill on delamination in drilling composite material"; International Journal of Machine Tools \& Manufacture, vol. 45, 2005, pp 125-130.

[21] C.C. Tsao, H. Hocheng, "The effect of chisel length and associated pilot hole on delamination when drilling composite material"; International Journal of Machine Tools \& Manufacture, vol. 43, 2003, pp 1087-1092.

[22] M. K. A Mohd Ariffin, M. I. Mohd Ali, S. M. Sapuan and N. Ismail, “An optimise drilling process for an aircraft composite structure using design of experiments"; Journal of Scientific Research and Essay, vol. 4 (10), 2009, pp 1109-1116.

[23] N. S. Mohan, A. Ramachandra and S. M. Kulkarni, "Influence of process parameters on cutting force and torque during drilling of glass-fiber polyester reinforced composites"; Journal of Composite Structures, Vol. 71, 2005, pp 407-413.

[24] Byoung Jung Kim and Dai Gil Lee, "Characteristics of joining inserts for composite sandwich panels"; Journal of Composite Structures, vol.86, 2008, pp 55-60.

[25] A. Paolozzi and I. Peroni, "Experimental assessment of debonding damage in a carbon - fibre reinforced plastic sandwich panel by frequency variations"; Journal of Composite Structures, vol.35, 1996, pp 435-444.

[26] Giuseppe Demedio, Katia Genovese and Carmine Pappalettere, "An experimental investigation of static and fatigue behavior of sandwich composite panels joined by fasteners"; Journal of Composite Part B, vol. 32, 2001, pp 299-308.

[27] S.C. Sharma, M. Krishna, H.N. Narasimha Murthy, M. Sathyamoorthy, and Debes Bhattacharya, "Fatigue studies of polyurethane sandwich structures"; Journal of Materials Engineering and Performance, vol. 13, 2004, pp 637-641.

[28] A.C. Manalo, W. Karunasena and M.M. Islam, "Flexural behaviour of structural fiber composite sandwich beams in flatwise and edgewise positions"; Journal of Composite Structures, vol. 92, 2010, pp 984-995. 